\title{
A Learning Patterns Perspective on Student Learning in Higher Education: State of the Art and Moving Forward
}

\author{
Jan D. Vermunt ${ }^{1}$ (D) Vincent Donche $^{2}$ \\ Published online: 3 May 2017 \\ (C) The Author(s) 2017. This article is an open access publication
}

\begin{abstract}
The aim of this article is to review the state of the art of research and theory development on student learning patterns in higher education and beyond. First, the learning patterns perspective and the theoretical framework are introduced. Second, research published since 2004 on student learning patterns is systematically identified and reviewed. This part includes two main sections. In the first section, new evidence on internal and external relationships of learning patterns is reviewed. Four themes are covered here: the dimensionality and the internal relationships of learning patterns and relationships of learning patterns with personal, contextual, and outcome variables. In the second section, new directions in learning patterns research are examined. These include studies on learning patterns in new international contexts and populations, longitudinal development of learning patterns over time, methodological advances in learning patterns research, and studies on fostering the quality of students' learning patterns. Next, relationships with adjacent theories on student learning are discussed, the learning patterns perspective is critically examined, and pathways are derived to move the model forward. Finally, future conceptual and methodological directions for learning patterns research are derived.
\end{abstract}

Keywords Learning patterns · Learning strategies · Conceptions of learning $\cdot$ Learning orientations $\cdot$ Learning motivation $\cdot$ Metacognition $\cdot$ Self-regulated learning

Jan D. Vermunt

jdhv2@cam.ac.uk

Vincent Donche

Vincent.donche@uantwerpen.be

1 Faculty of Education, University of Cambridge, 184 Hills Road, Cambridge CB2 8PQ, UK

2 Faculty of Social Sciences, Department of Training and Education Sciences, University of Antwerp, Sint Jacobsstraat 2-4, 2000 Antwerp, Belgium 


\section{Introduction}

A learning pattern is conceptualized as a coherent whole of learning activities that learners usually employ, their beliefs about learning and their learning motivation, a whole that is characteristic of them in a certain period of time. It is a coordinating concept, in which the interrelationships between cognitive, affective, and regulative learning activities, beliefs about learning, and learning motivations are united. In our 2004 article in Educational Psychology Review, the research conducted until then on patterns in student learning, mostly in higher education, was reviewed. More specifically, the review focused on a series of studies that had in common the use of the Inventory of Learning Styles (ILS), an instrument measuring four components of student learning patterns, and an integrative learning theory focusing on the interplay between self-regulation and external regulation of learning processes as a theoretical framework (Vermunt and Vermetten 2004).

The learning patterns framework is firmly rooted in two research traditions in the late 1970s and early 1980s. The first is the work by scholars mainly from the UK, Sweden, and Australia on approaches to learning and conceptions of learning, which later became known as the Student Approaches to Learning (SAL) tradition. In this tradition, student learning was mainly conceptualized in terms of cognitive strategies and motivation (e.g. Biggs 1987; Entwistle and Ramsden 1983; Marton and Säljö 1984; Pask 1988; Schmeck 1988). The second pillar was the early work on metacognition (e.g. Brown 1987; Flavell 1987; Friedrich and Mandl 1986; Palinscar and Brown 1984), which later developed into a tradition known as Self-Regulated Learning (SRL). In this line of work, scholars were interested in children's metacognitive knowledge and beliefs and their self-regulated learning strategies. Initially, this research was not focused on student learning in higher education. In our early conceptualisations of the learning patterns model, we tried to bridge these two research traditions in a more unified theoretical and empirical framework, bringing together cognitive strategies, regulation strategies, motivation, metacognitive knowledge, and learning conceptions (e.g. Vermunt 1987; Vermunt and Van Rijswijk 1988). The framework was one of the first to bring together these different research traditions, calling for the interrelated study of for example students' cognitive processing strategies and metacognitive regulation strategies.

Since 2004, the research on learning patterns has further flourished. The current review article is intended to cover research published between 2004 and 2016 on student learning patterns. In that period, research in this area has proliferated into several directions. A broader array of cultural contexts has been investigated than the dominant Western cultural contexts until then, for example in China, Columbia, Hong Kong, Mexico, and Sri Lanka (e.g. Law and Meyer 2011a). A broader array of learning contexts has been studied than the hitherto dominant first years of higher education, for example upper secondary, higher vocational and adult education, and apprenticeship and professional contexts (e.g. Gijbels et al. 2014). More longitudinal research has been conducted with longer time intervals and multiple measurements to track down developmental patterns in student learning patterns (e.g. Fryer et al. 2016). More advanced statistical techniques have been used for data analysis investigating the constituent aspects of learning patterns and development of learning patterns over time (e.g. Coertjens et al. 2013b). New instruments have been developed to measure aspects of learning patterns in a more parsimonious and online way (e.g. Endedijk et al. 2016). Finally, intervention research has been conducted aimed at fostering the development of certain learning patterns and discouraging other patterns (e.g. Donche et al. 2012). 
For this review article, a systematic literature search has been conducted to identify empirical and theoretical work and advancements in learning patterns research using the ILS inventory in the reference period (2004-2016). The main goals of this study are as follows: (1) to describe the current state of the art of the theory on student learning patterns; (2) to map the existing empirical evidence in the current field and trace the nature of research tendencies; (3) to critically reflect on the learning patterns perspective, and (4) to identify conceptual and methodological directions for future learning patterns research.

\section{Theoretical Framework: the Learning Patterns Perspective on Student Learning}

In the learning patterns theoretical framework, four components of student learning are discerned: cognitive processing strategies, metacognitive regulation strategies, (metacognitive) conceptions of learning, and learning motivations or orientations. Processing strategies are those combinations of cognitive learning activities that students employ to process subject matter and that lead directly to knowledge, understanding, and skill. Regulation strategies are those combinations of metacognitive learning activities that students use to plan, monitor, steer, and evaluate their cognitive learning processes and which indirectly lead to learning outcomes. Conceptions of learning are the metacognitive views and beliefs students hold about learning, teaching, and related phenomena. Learning motivations or orientations encompass the aims, goals, motives, and worries of students in relation to their studies, and they represent the motivational-affective component of the model.

In Fig. 1, a model of student learning is depicted. The core of the model is formed by a learning pattern. The learning strategies that students employ to process subject matter are regulated by metacognitive strategies, which are in turn influenced by students' conceptions of learning and learning motivations. These learning patterns lead to learning outcomes, and are influenced by various personal and contextual factors. Learning outcomes may constitute input for new learning processes. If the context changes, learning patterns may change as well (Vermunt and Vermetten 2004). To emphasize the dynamic nature of the model, all arrows between the elements are depicted as bidirectional. Of course, some personal factors like age will not change as a result of student learning. However, other personal factors like beliefs about the nature of intelligence can both influence the way students learn, as well as be influenced by student learning processes.

We conceive a learning pattern definitely not as a hard-to-change human trait, but as the result of the interplay between personal and contextual influences (Coffield et al. 2004; Vermunt and Endedijk 2011). In earlier publications, we used the term 'learning style' to denote this coordinating concept, but many people conceive learning style as an unchangeable human trait, deeply rooted in our personality or even biology (Coffield et al. 2004; Evans and Vermunt 2013). For this reason, around 2004, we stopped using the term learning style and introduced the concept of learning pattern as a more dynamic term to refer to this interrelated whole of students' learning strategies, views, and motives (Vermunt and Vermetten 2004).

In qualitative and quantitative empirical studies with university students, Vermunt (1996, 1998) studied the various components and developed the ILS inventory to enable the measurement of these components on a larger scale. Table 1 presents the four components of the instrument, the scales within each component, and a short description of the content of the scales. Since at the time that the instrument was developed we still used the term style instead of pattern, the name of the instrument has been kept the same to avoid confusion. For 


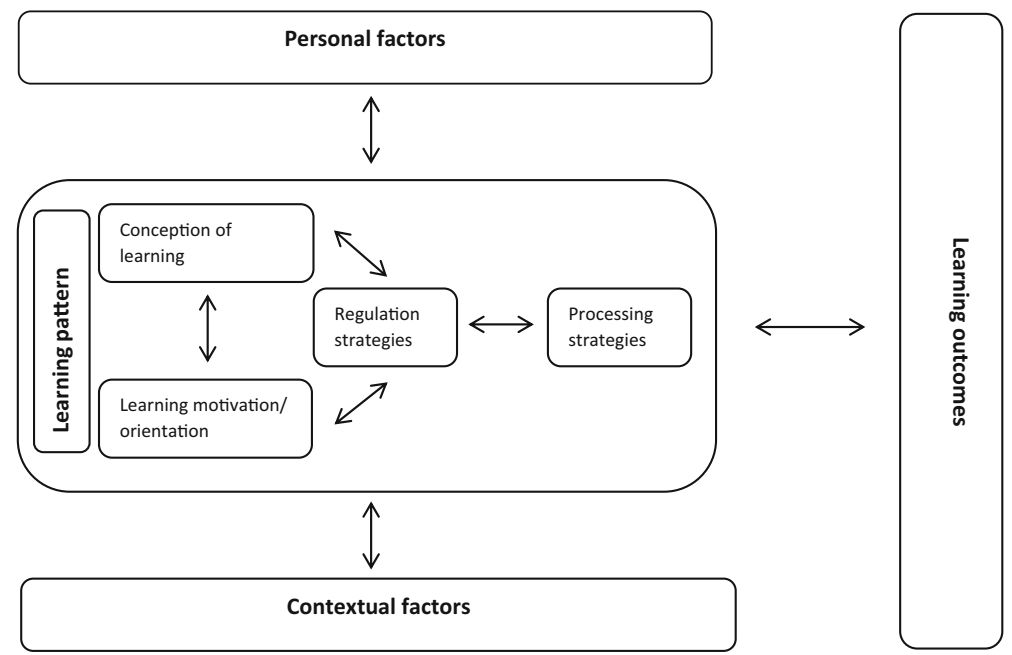

Fig. 1 A learning patterns model of student learning

the empirical base of the ILS, see Vermunt (1996) and (Vermunt 1998); for the theoretical background, see Vermunt and Verloop (1999).

Research on student learning in higher education has repeatedly identified four qualitative different patterns in the way students learn: reproduction-directed learning, meaning-directed learning, application-directed learning, and undirected learning (e.g. Lonka et al. 2004; Richardson 2000; Vermunt 1998). In reproduction-directed learning, students try to remember the learning contents to be able to reproduce them on a test. They memorize the learning materials and go through the study materials in a sequential way, step by step, without thinking much about relations between larger units. They pay a lot of attention to the regulation provided by teachers, study materials, and other external agents. Their motive for learning is to pass the test or to test their capabilities. They view learning mainly as the intake of knowledge from an external source to their own head, keeping it as closely as possible to the original. This learning pattern is defined by the ILS scales stepwise processing (consisting of the subscales 'memorizing and rehearsing' and 'analysing'), external regulation (with subscales referring to learning processes and outcomes), intake of knowledge as learning conception, and certificate directed and self-test directed learning orientations.

Students who learn in a meaning-directed way adopt a deep approach to learning: they try to understand the meaning of what they learn, try to discover relations between separate facts or views, structure the learning material into a larger whole, and try to critically engage to what they learn. They learn in a self-regulated way, not limiting themselves to the prescribed materials. They view learning as their own construction of knowledge for which they are mainly themselves responsible. Often they are motivated through personal interest for the topics of their studies. This learning pattern is defined by the ILS scales deep processing (with subscales 'relating and structuring' and 'critical processing'), self-regulation (with subscales referring to learning processes/outcomes and learning contents), construction of knowledge as learning conception, and personal interest as learning orientation.

Students who learn in an application-directed way try to discover relations between what they learn and the world outside. They try to find examples of what they study and think about how they would be able to apply what they learn in practice. Both more self-regulated and 
Table 1 Learning components, scales, and a description of their content of the ILS (from Vermunt and Vermetten 2004)

Learning components

Scales of the ILS

Description of content

Processing strategies

Deep processing

Relating and structuring

Critical processing

Stepwise processing

Memorizing and rehearsing

Analysing

Concrete processing

Regulation strategies

Self-regulation

Learning process and outcomes

Learning contents

External regulation

Learning process

Learning outcomes

Lack of regulation

Conceptions of learning

Construction of knowledge

Intake of knowledge

Use of knowledge

Stimulating education

Cooperative learning

Learning orientations

Personally interested

Certificate oriented

Self-test oriented

Vocation oriented

Ambivalent

Relating elements of the subject matter to each other and to prior knowledge; structuring these elements into a whole

Forming one's own view on the subjects that are dealt with, drawing one's own conclusions, and being critical of the conclusions drawn by textbook authors and teachers

Learning facts, definitions, lists of characteristics, and the like by heart by rehearsing them

Going through the subject matter in a stepwise fashion and studying the separate elements thoroughly, in detail and one by one

Concretising and applying subject matter by connecting it to one's own experiences and by using in practice what one learns in a course

Regulating one's own learning processes through regulation activities like planning learning activities, monitoring progress, diagnosing problems, testing one's outcomes, adjusting, and reflecting

Consulting literature and sources outside the syllabus

Letting one's own learning processes be regulated by external sources, such as introductions, learning objectives, directions, questions, or assignments of teachers or textbook authors

Testing one's learning outcomes by external means, such as the tests, assignments, and questions provided

Monitoring difficulties with the regulation of one's own learning processes

Learning viewed as constructing one's own knowledge and insights. Most learning activities are seen as tasks of students.

Learning viewed as taking in knowledge provided by education through memorizing and reproducing; other learning activities are tasks of teachers.

Learning viewed as acquiring knowledge that can be used by means of concretising and applying. These activities are seen as tasks of both students and teachers.

Learning activities are viewed as tasks of students, but teachers and textbook authors should continuously stimulate students to use these activities.

Attaching a lot of value to learning in co-operation with fellow students and sharing the tasks of learning with them

Studying out of interest in the course subjects and to develop oneself as a person

Striving for high study achievements; studying to pass examinations and to obtain certificates, credit points, and a degree

Studying to test one's own capabilities and to prove to oneself and others that one is able to cope with the demands of higher education

Studying to acquire professional skill and to obtain a(nother) job

A doubtful, uncertain attitude toward the studies, one's own capabilities, the chosen subject area, the type of education, etc. 
externally regulated variants of this pattern exist. What is common, however, is the great value these students attach to learning to use the knowledge they acquire; knowledge they cannot use is of much less value to them. Vocational motives often underlie this pattern: students want to prepare themselves for a profession or they want to become better in their current job. This learning pattern is defined by the ILS scales concrete processing, the learning conception use of knowledge, and a vocational learning orientation.

Students who learn in an undirected way do not know well how to approach their studies. This pattern can often be seen with students who are in transition from one form of schooling to another, for example from secondary to higher education, from undergraduate to graduate studies, or students coming from another country with different pedagogical practices (Biemans and Van Mil 2008; Vermunt 1998). They try to adopt the approach they are used to previously, realize that this approach is not adaptive in the new circumstances, but do not know well how to learn in a better way. They often experience a lack of regulation, doubt whether they are able to cope with the demands of the new learning environment, and attach great value to fellow students and teachers to offer the direction and hold they miss so much. This learning pattern is defined by the ILS scales lack of regulation, the learning conceptions emphasizing stimulating education and cooperative learning, and an ambivalent learning orientation (Vermunt and Vermetten 2004).

The learning patterns perspective is grounded in a variable-oriented research perspective, which means that based on factor analysis, latent factors can be distinguished which are reflecting coherent and correlated patterns between distinguishing scales. The resulting dimensions or learning patterns must be seen as prototypical dimensions, and particular students may exhibit features of more or less patterns. Some students exhibit all features of one particular pattern; others are more versatile and show characteristics of two or even more patterns. Learning patterns are not mutually exclusive regarding the constituent scales. Therefore, combinations of learning patterns might be present among specific subgroups of students (e.g. Donche and Van Petegem 2009; Fryer et al. 2016).

Research on student learning has shown that several personal and contextual factors influence the learning patterns that students adopt. Among the personal factors are age, knowledge of subject matter, and educational experience. Important contextual factors influencing students' learning are for example the teaching methods used, type of assessment, and opportunities to collaborate with other students. Students' learning processes also prove to be related to the learning outcomes they attain. Research has for example shown that exam results are often positively related to many features of the meaning-directed learning pattern (students' relating and structuring activities, selfregulation, critical engagement) and analytical processing. Exam results show consistent and negative relations with students' lack of regulation and ambivalent learning orientation, two features of the undirected learning pattern (e.g. Vermunt and Vermetten 2004).

Vanthournout et al. (2014) discussed the differences and similarities between learning patterns and approaches to learning. Compared to related concepts, a learning pattern represents a more holistic notion. As noted above, earlier conceptualisations of student learning in the SAL-tradition focused on cognitive strategies and motivation (e.g. Biggs 1987; Entwistle and Ramsden 1983; Schmeck 1988). Compared to these earlier conceptualisations, both metacognitive strategies (i.e. regulation of learning) and metacognitive knowledge (i.e. conceptions of learning) are included in this broader notion of learning patterns. Moreover, the recognition of application-directed learning and undirected learning as important dimensions of student learning and the clarification of interrelations between different processing and regulation strategies are important extensions of the learning patterns framework compared to the SAL models. 
Some of the concepts used in the learning patterns framework are similar to key concepts in SRL models (see also Zusho 2017), due to their common roots in early metacognition research. However, there are important differences between both models as well. Compared to the SRL-tradition on metacognition, the learning patterns model is less normative. Basically, the SRL model is unidimensional and posits one ideal way of learning, namely self-regulated learning, while the learning patterns model is multi-dimensional and grounded in students' experiences of learning in normal study settings, where four different patterns emerged to exist. Secondly, the learning patterns model postulates not only self-regulated learning but also two other forms of regulation, external regulation, and lack of regulation, thereby representing a broader conceptualisation of regulation of learning, again rooted firmly in empirical research on students' experiences in real-life study contexts. Thirdly, the learning patterns model does not limit the conceptualization of learning processes to regulation. Instead, a core focus of the learning patterns model is the interrelationships between processing and regulation strategies. Within the learning patterns model, a four-component distinction (processing, regulation, conceptions, and motives) is made which is further operationalized in specific concepts which are not all present in current SRL models. For instance, application-directed and undirected learning dimensions and concrete processing, external regulation, lack of regulation, and ambivalent orientation are elements not present in most SRL models.

Vermunt and Endedijk (2011) recently expanded the learning patterns perspective to the domain of teacher learning. In a study on Hong Kong students in post-secondary education, Law and Meyer (2011a) concluded that their findings buttress the learning patterns theoretical model of student learning. Although the concepts come from different research traditions (SAL and SRL), in this review, 'approach to learning' and 'processing strategy' will be used more or less interchangeably.

The aim of this paper is to review the state of the art of research and theory development on the student learning patterns theoretical framework. Therefore, the current paper focuses on research conducted since 2004 on student learning patterns. In line with the aims of this special issue and request of the guest editors, this study focuses moreover on empirical studies in which (parts of) the ILS was used as a tool to capture differences in student learning.

\section{Method}

Two databases were included for the current literature search: ERIC (Ebsco) and Web of Science in which also the Social Science Citation Index (SSCI) is included. We chose 2004 as a starting point, since the former review study of Vermunt and Vermetten (2004) reported on previous ILS research in the field, and incorporated research published until the end of 2016. We used a combination of search terms related to the model of learning patterns, and given the focus of the review study, the search terms were combined with the search term Inventory of Learning Styles (ILS) as primary target for the review study (see Table 2).

Of course self-report instruments have their limitations, as have other methods. Think-aloud protocols are often used in artificial experimental settings with low ecological validity. Logging students' interactions with Virtual Learning Environments (VLEs) may reveal that they have opened a particular VLE-page for a certain amount of time, but this does not give much information about their mental activities during that time. Eye-tracking may reveal what students are looking at, but not what they are thinking about (e.g. Catrysse et al. 2016). It is rather a question for what kind of purpose specific measurement tools need to be used. A 
Table 2 Overview of literature search terms and hits (September 2016)

\begin{tabular}{lll}
\hline & $\begin{array}{l}\text { Search engine } \\
\text { Web of science }\end{array}$ & ERIC \\
\hline Inventory of learning styles & 368 & 204 \\
And learning pattern & 42 & 16 \\
And learning strategies & 96 & 60 \\
And learning conception & 26 & 8 \\
And learning orientation & 30 & 9 \\
And processing strategies & 28 & 9 \\
And regulation strategies & 21 & 8 \\
Total & 611 & 314 \\
Overall total & & 925 \\
\hline
\end{tabular}

strong point of the ILS compared to similar and different instruments is that it was grounded in interview research with the target student population about their learning in natural, real-life settings. In addition, many studies using the ILS or similar instruments (such as the Motivated Strategies for Learning Questionnaire (MSLQ), Study Process Questionnaire (SPQ), Revised Approaches to Studying Inventory (RASI)) have found relations between self-reported learning strategies and actual learning activities or hard outcome variables. As was mentioned above, around 2004, we realized that learning 'style' is not an appropriate term for the phenomenon of interest, and therefore renamed it in 2004 into learning 'pattern' to emphasize its more dynamic nature. However, the ILS has kept its name in the reviewed research literature, although Inventory of Learning Patterns (ILP) would have been a better name for the research instrument.

The initial search retrieved 925 articles published within the period of 2004 and September 2016. In a second step, elimination of double records took place, using EndNote software, leaving 441 studies useful to be screened. In a next step, evaluation took place of all titles and abstracts to investigate whether the research reported had (1) a clear link to the learning patterns framework, and more specifically using the ILS inventory; (2) a sound empirical base, in which the use of (parts of) the ILS inventory is present; and (3) a clear description of method and result section. A majority of studies referring to Kolb's Learning Styles Inventory (LSI) were deleted from this analysis. Articles in which the ILS inventory was used in the empirical part of the study were retained. In a final step, citation and author searches and backward snowballing were used based on the reference list of retrieved articles as well as state-of-the art publications regarding learning patterns research (e.g. Gijbels et al. 2014), in order to identify other relevant learning pattern studies. Also, these studies were subject to the above-mentioned inclusion criteria. This resulted in a total set of 44 learning pattern studies in which the ILS was used (included in the reference list with asterisk symbol).

\section{Results}

The studies in the final set could be grouped into two main categories. First, there were studies following up the learning patterns research reviewed in the 2004 paper, aiming to further advance our knowledge about the internal and external relationships of learning patterns in more detail in new samples. These studies can be seen as a continuation of the research themes identified in the 2004 review. Four of these themes will be covered here, in accordance with the model presented in Fig. 1: the dimensionality and internal relationships of learning patterns 
(the core of the model) and relationships of learning patterns with personal, contextual, and outcome variables. Second, there were studies into new directions compared to the 2004 review. These refer to studies investigating the learning patterns model in new international contexts and populations, longitudinal studies on the development of learning patterns over time, studies investigating methodological advances in learning patterns research, and studies on fostering the quality of students' learning patterns. For reasons of clarity, the different research themes are separately discussed below, but in many of the studies, more than one of these research themes could be identified.

\section{New Evidence on Internal and External Relationships of Learning Patterns}

\section{Internal Relationships and the Dimensionality of Learning Patterns}

The four learning patterns as described above are defined by the specific interrelations between learning components. Several studies in the last decade have looked into these interrelations into more detail in new samples. Overall, they confirm the strong interrelations between students' processing and regulations strategies, learning conceptions, and learning motivations that form the core of the learning patterns model (Edelbring 2012).

For example, in a problem-based curriculum, Loyens et al. (2008) found structural positive relations between Dutch students' constructive conceptions of learning on the one hand and their use of deep processing and self-regulation strategies on the other hand. The learning conceptions 'construction of knowledge' was negatively related to external regulation and lack of regulation. Finally, they found that students who were doubtful about their own learning capacities tended to adopt an inadequate regulation strategy. Similarly, Heikkilä et al. (2011) found significant relations between Finnish students' deep approach to learning and a selfregulated learning strategy, while there was no relation between self-regulation and a surface approach to learning. Richardson (2010) found a strong relation between students' conceptions and approaches among students in British distance education. Again, a deep approach to studying was strongly related to a constructive conception of learning, and a surface approach was strongly related to a conception in which learning was seen as the intake of knowledge. Zhu et al. (2008) found that a surface approach to learning was related to a conception of learning as 'remembering', and a deep approach to learning to conceptions of learning as 'understanding' and 'personal change' among both Chinese and Flemish first year university students. Richardson (2007) evaluated the learning conceptions section of the ILS with students from the British Open University. In line with theory, five homogeneous and theoretically sound learning conception scales could be distinguished in the data. A cluster analysis revealed four subgroups of students in terms of their learning conceptions, corresponding to the four learning patterns described above.

In some studies from non-Western countries, similar interrelations between learning pattern components were found. For example, in a sample with Hong Kong post-secondary students, Law and Meyer (2011b) found empirical support for the learning patterns theoretical model underpinning the ILS. They concluded that their findings particularly confirmed the central explanatory role of regulation strategies in students' learning patterns, as hypothesized by the model. Gulpinar (2014) reported the replication of the four dimensions of learning patterns among preclinical medical students in Turkey.

In summary, overall, these studies confirm the interrelations among processing and regulation strategies, learning conceptions, and learning orientations that were identified in 
the review of Vermunt and Vermetten (2004) with new samples. The research has focused especially on elements of the meaning-directed, reproduction-directed and undirected dimensions, and less on those of the application-directed dimension. Together, these studies provide further evidence for the underlying dimensionality of learning patterns as described above.

\section{Relations of Learning Patterns with Personal Factors}

Many studies published since 2004 have generated new evidence on the relation between the students' learning patterns and a variety of personal factors. These personal factors included personality, academic motivation, goal orientation, attributions of academic success, selfefficacy, effort, epistemological and intelligence beliefs, prior education, age, and gender.

Among the personality factors that are associated with aspects of learning patterns are openness to experience, conscientiousness, and neuroticism. Several studies found that openness to experience is positively related to students' use of self-regulated and deep processing strategies, conscientiousness is positively related to the use of an analytic processing strategy, and neuroticism is positively related to lack of regulation (Donche et al. 2013; Catrysse et al. 2015). The strength of these associations is weak to moderate which provides further evidence that learning patterns are not stable traits. Donche et al. (2013) and Catrysse et al. (2015) also included academic motivation as conceptualized within self-determination theory (Vansteenkiste et al. 2006) as a predictor of students' learning strategies. They found that autonomous motivation had a positive effect on the development of all cognitive processing strategies and self-regulation. Controlled motivation was positively related to the development of stepwise processing and lack of regulation. Amotivation turned out to be related to the development of lack of regulation. In a longitudinal study on a large sample of Japanese students, Fryer et al. (2016) found that students' self-regulation and lack of regulation were important predictors of their future motivations. For example, self-regulation predicted future belief in own ability, the necessity to exert effort, and the valuation of study tasks. De Clercq et al. (2013) found that students' mastery goal orientation increased their subsequent use of self-regulated and deep processing strategies.

Students' learning patterns turn out to be associated with their attributions of academic success and self-efficacy. A clear pattern of interrelationships emerged from a study by Ferla et al. (2008) among a large sample of students at a Belgian university, with a central role for students' learning conceptions. Students with a constructive conception of learning made more use of both self-regulation and external regulation strategies, more often adopted a deep approach to learning, attributed their academic outcomes more often to effort, and felt more self-efficacious than other students. When students agreed more with a reproductive conception of learning, they made more use of a surface approach to learning, they more often adopted an external regulation strategy, they attributed academic success more often to uncontrollable causes such as difficulty level of examinations, and they felt less selfefficacious than other students. Similar results were reported by Heikkilä et al. (2011) in a study adopting a person-oriented approach among Finnish university students.

Epistemological beliefs are beliefs and views on the nature of knowledge in a more general sense (Perry 1970; Van Rossum and Hamer 2010). In a study among Chinese and Belgian students, Zhu et al. (2008) found that students' belief that knowledge is certain was related to a reproductive conception of learning, which predicted a surface approach to learning. The belief that the ability to learn can be developed was related to constructive conceptions of learning, which predicted students' use of a deep approach to learning. Dahl et al. (2005) found similar 
relations between students' epistemological beliefs and their reported use of learning strategies in a sample of Norwegian university students. Stump et al. (2014), in a sample of US engineering students, found that students' incremental beliefs about intelligence (the belief that intelligence can grow) correlated positively with deep processing strategies and collaborative learning strategies, whereas entity beliefs (the belief that intelligence is fixed) about intelligence correlated negatively with both these learning strategies. Deep processing and to a lesser extent collaborative learning were both positively associated with self-efficacy.

Students' learning patterns are also associated with their prior education, age, and gender, but different learning patterns have different origins. In a large-scale study among university students in The Netherlands, Vermunt (2005) found that age was an important predictor of almost all aspects of meaning-directed learning. The older the students were, the more they adopted a meaning-directed learning pattern. Concerning gender, the main difference between men and women showed up in their appreciation of cooperative learning: female students attached more value to cooperative learning than males. With regard to highest level of prior education, he found that students showed less signs of reproduction-directed learning when their level of prior education was higher. Concerning undirected learning, Vermunt's (2005) results showed that lower educated students showed more characteristics of lack of regulation than higher educated students. In a large-scale study among university college students in Belgium, Donche et al. (2014) found that students who had been prepared for academic tracks in secondary education showed less signs of reproduction-directed learning than students prepared for vocational or technical education tracks. To some extent, these relations may be culturally dependent. For example, Law and Meyer (2011a) found more gender differences in a large sample of Hong Kong students. Male students scored higher on four of the five processing strategy scales (except memorizing) and on both self-regulation scales. Female students scored higher on four of the five learning conception scales (except cooperative learning) and four of the five learning motivation scales (except ambivalence). The authors suggested that male Hong Kong students tend more to be active learners, and female Hong Kong students tend more to be passive learners.

In summary, as the model in Fig. 1 predicts, the empirical studies discussed above have shown that the learning patterns that students adopt are embedded in a range of personal factors such as personality, academic motivation, goal orientation, attributions of academic success, self-efficacy, effort, epistemological and intelligence beliefs, prior education, age, and gender. This does not mean that learning patterns are hard to change. It probably means that they do not change from day to day and that there is some stability associated with them. On the other hand, many of these personal factors may develop as well. Motivations, orientations, beliefs, and attributions are phenomena that are malleable over time. Even contemporary conceptions of personality entail the possibility of growth and development. The evidence points to learning patterns as a phenomenon with some stability, but with potential for change, growth and development as well. Further evidence for this conclusion will be reviewed in the next sections on contextual influences and development.

\section{Relations of Learning Patterns with Contextual Factors}

In accordance with the model in Fig. 1, research since 2004 has also generated new evidence for relations between the learning patterns that students adopt and contextual features. Among the contextual factors included in this research were teaching strategies, perception of the learning environment, and disciplinary differences. 
Teachers' teaching strategies influence the learning strategies students adopt. In a largescale study, Donche et al. (2013) asked 90 lecturers in a university college about their use of teaching strategies, and 1126 undergraduate students in the same college about their use of learning strategies. They used two teaching strategies scales: direct instruction (high teacher control over students' learning, highly transmission oriented, content-focused approach to teaching), and learning-focused (enabling students to take more control of their learning, learning-focused, student-focused approach to teaching). After controlling for personality traits and academic motivation, in study disciplines where lecturers applied more direct instruction, students scored lower on the use of external regulation. Students within disciplines in which teachers were more learning focused in their teaching scored higher on all processing strategies and were more regulated (self or external) in their learning. The first mentioned outcome seems puzzling at first, but may be explained by the strong presence of external control in the learning environment in the first years of higher education, leaving little strategic choice for students to make more or less use of this control. The second finding is more straightforward and may point to the activating effect of giving students control over their own learning decisions.

Students' perceptions of the learning environment are associated with the learning patterns they adopt. Law and Meyer (2011a) investigated these relations for a large group of Hong Kong students. 'Good teaching' showed positive correlations with 18 out of 20 ILS scales (the exceptions being an ambivalent learning orientation and lack of regulation, two elements of the undirected learning pattern). The higher (and more inappropriate) the students perceived their workload, the more undirected learning they reported. Similar relations showed up for 'appropriate assessment'. Moreover, the more students viewed assessment as inappropriate, the more their learning pattern was reproductive in nature. 'Emphasis on independence' showed the strongest and positive relations with all aspects of the meaning-directed learning pattern. Finally, 'generic skills' showed the strongest relations not only with all elements of the application-directed learning pattern but also with meaning-directed and reproduction-directed learning. Konings et al. (2011) studied relations between preferences for and perceptions of teaching and aspects of learning patterns in a large sample of high school students (mean age 16 years) in the Netherlands. They found many of these relations. Some noteworthy ones are the positive relation between deep processing and a preference for integration, the negative relation between stepwise processing and a preference for productive learning, and the positive relation between a certificate-directed learning orientation and a preference for clear goals. In a longitudinal follow-up study, a remarkable drop in students' preference for student autonomy could be observed, which could possibly be explained by a failed educational innovation in this country during the years of the study aiming at fostering students' active and self-regulated learning. The drop was larger for students with a certificate-oriented motivation and smaller for students high on self-regulation (Konings et al. 2012).

Students' perception and appreciation of the learning environment may be dependent on their current learning pattern. A study by Edelbring and Wahlström (2016) showed that students high on self-regulation generally perceived the benefits of a web-based virtual patient medical education setting in Sweden, especially under a shared teacher regulation setting. On the other hand, students high on external regulation saw most benefits of the virtual patient activity in a strongly teacher regulated setting. The authors concluded that external teacher and peer regulation can be helpful for increasing learners' perceived benefit and that the flexible student-autonomous character of the virtual patients' pedagogy should not lead to the dismissal of guidance and related course activities. 
Disciplinary differences are associated with the learning patterns students adopt. In a largescale study, Vermunt (2005) compared the learning patterns of students of seven different disciplines at a Dutch university specialized in societal sciences. Arts and Psychology students showed most characteristics of meaning-directed learning, students of Economy and Econometry the least. Reproduction-directed learning was found most among students Law and Econometry and least among students from Arts and Psychology. Law students showed most features of application-directed learning, students of Arts the least. Finally, undirected learning was found most among students of Economy and Econometry and the least among Law students. Vermunt (2005) explained these disciplinary differences in the learning patterns students adopt by a combination of differences in the nature of the discipline, differences in dominant pedagogical practices in the different disciplines, and differences between the students who choose to study particular disciplines. Smith et al. (2007) found a strong dominance of application-directed learning among Pharmacy students in Australia for all year groups, a dominance that stayed stable throughout the study. This finding shows similarities with results from Lindblom-Ylänne and Lonka (2000), who found a clear and separate application-directed learning factor among advanced and adult medical students. Timarova and Salaets (2011) found that applied language students' in Belgium studied more according to a reproduction-directed pattern than a meaning-directed pattern, and Vilppu et al. (2013) found that Finnish teacher students reported more deep processing than stepwise processing in their studying of textbooks.

In summary, these studies provide further evidence that students' learning patterns are related to environmental factors. Many of these studies were correlational in nature so the direction of influence can go in several ways. It may be that the environment influences the learning patterns students adopt, it may be that students with certain learning patterns tend to choose particular environments or disciplines, and it may even be that teachers adapt their teaching to accommodate students' dominant learning patterns and preferences. Probably, the relationships are reciprocal. Some of the relationships that were found were more or less logical, others were unexpected, surprising and puzzling. The last two mentioned examples above show that these environmental influences may operate on a quite specific level through specific pedagogical arrangements. The contextual embeddedness of students' learning patterns may give indications for attempts to foster the quality of student learning. We will come back on this possibility in the paragraph with a similar heading.

\section{Relations of Learning Patterns with Learning Outcomes}

Learning patterns prove to be an important predictor of variance in learning outcomes. Various studies show a clear pattern of relations that, overall, point in the same direction. Meaningdirected learning is generally positively related to various indicators of academic performance, in different academic disciplines. Reproduction-directed learning mainly shows negative relations with exam performance. Application-directed learning is rather neutral overall with regard to academic success in conventional university education. Undirected learning is consistently and negatively related to academic performance in all disciplines (e.g. Vermunt 2005). However, some relations may be rather discipline-specific. For example, in their study among Pharmacy students in Australia, Smith et al. (2007) found that especially applicationdirected learning had a significant and positive relationship with academic performance. In their study, both meaning-directed learning and reproduction-directed learning showed negative relationships with academic performance. 
Martínez-Fernández and Vermunt (2015) found in a large-scale study among student teachers in Latin America and Spain that students' use of deep processing strategies and their effort were positively and significantly related to academic performance, while self-regulation strategies turned out to be the best predictor of deep processing. Another aspect of the meaning-directed learning pattern, the learning conception construction of knowledge, also had a direct effect on academic performance in their Structural Equation Model. Viewing learning as intake of knowledge had a direct negative impact on academic performance. Donche et al. (2014) confirmed the expected positive relationship between deep processing and academic success in eight different professional bachelor programs, while lack of regulation negatively predicted academic success. Vanthournout et al. (2012) found that the relating and structuring learning strategy and the external regulation strategy both positively predicted academic success in a first-year professional bachelor program in Belgium and that lack of regulation predicted academic success in a negative way.

De Clercq et al. (2013), in a study among engineering students, found that self-regulation is especially important for explaining study success in the beginning of university studies. With a more advanced sample of engineering students in the third year of studies, they found that the past examination performance was the best predictor of current examination performance, a finding which is well documented in the research literature. Cano and Garcia Berbén (2014) brought forward the notion of dissonance in explaining study success, or actually study failure. In the context of learning patterns, dissonance means that for some groups of students their motives, conceptions, and strategies are not aligned (Vermunt and Vermetten 2004). For example, some students may combine a constructive conception of learning with a surface approach to studying, or personally interested motivation with lack of regulation. Previous research (e.g. Lindblom-Ylänne and Lonka 2000; Meyer 2000; Vermunt and Minnaert 2003) has shown that these students are at risk in terms of examination achievements, at least within the boundaries of Western cultures.

The relations between (aspects of) learning patterns and academic success can be quite different in different cultural contexts. For example, in a longitudinal study among first-year students from a Japanese university self-regulation did not predict GPA (Fryer et al. 2016). However, there was a positive relation between lack of regulation measured after 3 months and end-of-year GPA, and a negative relation between lack of regulation measured after 9 months and end-of-year GPA. External regulation measured after 9 months positively predicted endof-year GPA. In a study among Hong Kong students in post-secondary education, Law and Meyer (2011a) found, as expected, that most aspects of the undirected learning pattern were significantly and negatively associated with study success expectancies. However, two aspects of the reproduction-directed pattern were positively related to this success variable: external regulation of learning processes and a learning orientation focused on testing oneself.

In general, these studies show that meaning-directed learning is positively related to academic performance and undirected learning predicts academic performance in a negative way. Relations between academic performance and elements of reproduction-directed and application-directed learning are less consistent, and vary with, among other things, academic discipline, cultural context, and assessment method.

\section{New Directions in Learning Patterns Research}

Research on the internal and external relations of learning patterns in the reference period, as discussed above, can be seen as a continuation of learning patterns research that started earlier. 
This research has partly confirmed earlier findings in new contexts, and partly generated new evidence on a more specific level. However, research on learning patterns has moved into new directions as well, which will be discussed in the next section. These refer to studying learning patterns in new international contexts and populations, studies on the longitudinal development of learning patterns over time, studies exploring methodological advances in learning patterns research, and studies on fostering the quality of students' learning patterns.

\section{Learning Patterns in New International Contexts and Populations}

Since its development, the ILS has been translated into a variety of languages and used by researchers in different countries to study various aspects of learning patterns (e.g. Al-Kadri 2008). Many studies in this review were done in other cultural contexts than Western higher education. The review included student samples from Australia, Belgium, China, Colombia, Finland, Hong Kong, Indonesia, Japan, Mexico, the Netherlands, Norway, Saudi Arabia, Spain, Sri Lanka, Sweden, the UK, the USA, and Venezuela. Often, researchers have used similar data analysis techniques, so the results from the different studies can be compared. Basically two approaches have been adopted for such comparison. One is to compare the means on the ILS-scales among different populations, e.g. whether one sample scores higher or lower on deep processing than another sample. The other approach is to compare the interrelations of the ILS-scales among samples. In this case, one is interested whether the relations between the different elements of learning patterns differ among different populations, i.e. whether the relations between learning motives and processing strategies is the same or different in two populations.

Taking the first approach, Biemans and Van Mil (2008) compared the scores of Chinese and Dutch students at a Dutch university on the ILS-scales. They found that Chinese students scored higher than Dutch students on several scales characteristic of reproduction-directed and undirected learning, while the Dutch students as a group did not show a dominant learning pattern. Zhu et al. (2008) compared Chinese students at a Chinese university with Flemish students at a university in Flanders. They found that the Chinese students had higher means on scales measuring learning conceptions belonging to a meaning-directed learning pattern (understanding, personal change) than Flemish students. The Flemish students scored higher on surface approach, and there were no differences in a deep approach to learning. Marambe et al. (2012) compared three samples of university students in their mean ILS-scores, two Asian (Sri Lanka and Indonesia) and one European (Netherlands) sample. The results showed most differences between Asian and European students. However, many differences showed up between Indonesian and Sri Lankan students as well. They found no support for the stereotype 'Asian learner'. Since Sri Lankan students turned out to make least use of memorizing strategies of all groups, their results did not support the idea sometimes found in the literature that Asian students would have a propensity for rote learning.

Taking the second approach, Vermunt et al. (2014) performed a meta-analysis on studies with students from Hong Kong (Law and Meyer 2010), Indonesia (Ajisuksmo and Vermunt 1999), Sri Lanka (Marambe et al. 2012), Spain, Venezuela, Columbia and Mexico (MartínezFernández and Vermunt 2015), and The Netherlands (Vermunt 1998). Together these studies represented eight samples from eight different countries on three continents (Europe, Asia, and America). To answer the question whether learning patterns are universal across contexts and populations or whether different learning patterns emerge in different contexts and populations, Vermunt et al. (2014) compared the results of factor analyses on students' ILS- 
scores in all these studies. In most studies, a meaning-directed, a reproduction-directed, and an undirected pattern emerged, although these looked somewhat differently in different countries. This finding seems to support a previous observation by Richardson (1994) that a meaning and reproduction orientation to learning are universal across higher education systems but receive a specific interpretation in each system.

Besides the similarities across the contexts and populations, the comparison showed differences between students in different countries as well. While meaning-directed, reproduction-directed and undirected learning patterns seemed to be universal around the globe; three other patterns were observed that seemed to be more specific for particular contexts or populations. One of these was the already mentioned application-directed learning pattern, which was found mainly among adult students in the Dutch sample. However, clear application-directed learning dimensions have also been reported by Smith et al. (2007) among Pharmacy students at an Australian university and by Lindblom-Ylänne and Lonka (2000) among advanced medical students in Finland. Another pattern that showed up in many but not all samples was one combining all conceptions of learning, with almost no loadings from other scales. This was interpreted as a passive-idealistic learning pattern, since it only contained ideas about learning and no learning activity. Finally, in some samples, many or all learning orientations clustered on one factor, with few or no loadings from other scales. This phenomenon showed similarity with the clustering of many or all learning conception scales of the previous dimension, and therefore, this dimension was interpreted as a passive-motivational pattern.

One of the striking differences between samples was that in some countries, learning conception and learning orientation scales did not load on the same factors as the learning strategy scales, while in other countries, the factors were defined by loadings of scales coming from all four learning components: two behavioural components (the processing and regulation scales) conceptual or metacognitive components (the conception scales) and motivational components (the orientation scales). It seemed the case that in some countries, how students learn is strongly connected to what they think about learning and why they learn, while in other countries, what students do to learn is much less associated with what they think about and want to achieve with their learning. This may be related to for example differences between countries in freedom for students to choose their subject area, which is in some cultures more a family decision than an individual one.

Another remarkable difference between student groups from different countries was the degree of differentiation within the various learning components. For example, in some countries, students' views on learning were clearly loaded on different factors, pointing to a differentiated set of conceptions about learning. In other countries, all conceptions of learning clustered on one factor, indicating that their views about learning were highly interrelated. Research with Chinese students has for example shown that for them, memorization and understanding were not opposite poles. Instead, for these students, the essential difference was much more between mechanical memorization and memorization to assist development in meaning (Marton et al. 2005).

The differences in underlying dimensions between student groups from countries from the same continent were often larger than the differences between students from different continents. Again, the typical 'Asian', 'European', or 'Latin-American' student does not seem to exist. These outcomes are in line with the outcomes of Marambe et al. (2012) with a smaller sample of students from only three countries. Together, they point to strong contextual influences on the formation of student learning patterns. 
Although a lot of learning patterns research has focused on student learning in the first years of higher education, during the last decade, this research has also proliferated into other areas. Konings et al. (2012) and Könings et al. (2014) for example studied the learning patterns of tenth grade students in secondary schools in relation to their instructional preferences, while Helle et al. (2013) focused on high school students' development of personal interest and selfregulation. Endedijk et al. (2014b) focused on the learning patterns of teacher education students who were participating in a dual education programme combining study at university with internship (practice teaching) at a school. Very recently, Vrikki et al. (2017) studied experienced teachers' learning patterns who were participating in a Lesson Study professional development programme to implement innovations in their mathematics education. Often, these studies did not use the ILS as a measurement instrument since the context of learning deviated too much from the context of higher education for which the ILS was designed. Therefore, many of these studies are not included in this review (but see for example Vermunt and Endedijk (2011) for a review of learning patterns in teacher professional learning and development).

\section{Longitudinal Development of Learning Patterns Over Time}

Until a decade ago, longitudinal research on the development of student learning patterns was rare. The longitudinal research that was conducted often had a time interval of only a couple of months at most, and no more than two measurement points (e.g. Vermunt 1998). A similar trend has also been observed in longitudinal studies examining students' approaches to learning (see Asikainen and Gijbels 2017). However, during the last 10 years, longitudinal research has advanced considerably in both these aspects. The time intervals went up to 3 years, and the number of measurement points increased up to five, enabling the study of other type of developments than only linear ones.

Cross-sectional designs may demonstrate differences and similarities between different cohorts of students, but they cannot demonstrate developments within groups of students. Smith et al. (2007) studied Pharmacy students' learning patterns at an Australian university in a cross-sectional design. They administered the ILS to students in years 1, 2, 3, and 4 of studies. Results indicated significant differences between year groups for meaning-directed and reproduction-directed learning, but not for applicationdirected and undirected learning. Meaning-directed scores were lower in the years 2 and 3 groups compared to year 1 , but year 4 group scores for this learning pattern were higher than those of the other year groups. For reproduction-directed learning, year 1 group scores were significantly higher compared to those of the other year groups, but years 2, 3, and 4 group scores for this learning pattern were all similar to each other. The authors conclude that there was little evidence of maturation in learning patterns for these students as they progressed through the curriculum.

In a longitudinal design, Donche and Van Petegem (2009) administered the ILS twice to student teachers, once at the beginning of their first year and again at the end of their third year. The results indicated that aspects of meaning-directed learning (deep processing, selfregulation, construction of knowledge) increased over time. Also, concrete processing, an aspect of the application-directed learning pattern, increased significantly from year 1 to year 3. The degree to which students viewed learning as the intake of knowledge decreased over time, as did their experienced lack of regulation. The other aspects of reproduction-directed learning stayed rather stable during the research period. 
Developments in students' learning patterns do not always follow a linear path. A large sample of students from eight bachelor programmes at one university college in Belgium was followed by Donche et al. (2010) for 3 years. They noticed a development of many aspects of learning patterns, but most changes took place between years 2 and 3 and less between years 1 and 2. All measured aspects of meaning-directed learning increased from year 2 to year 3 (deep processing, self-regulation, construction of knowledge), reproduction-directed learning decreased consistently over all 3 years (intake of knowledge, external regulation, memorizing), concrete processing increased from year 2 to year 3, and lack of regulation decreased constantly over the 3 years. The use of an analysing strategy remained constant. These developmental trends seemed to vary dependent on students' initial learning pattern. Students seemed to change less in their meaning-directed learning than in their reproduction-directed learning. It were especially the students who initially scored high on reproductive and undirected learning who changed their learning patterns into the direction of more meaningdirected and application-directed learning. Students already high on meaning-directed and application-directed learning at the start changed much less throughout the years.

Learning patterns seem to change most when the learning environment changes most. When the environment stays rather constant, learning patterns are less inclined to develop. For example, in a longitudinal study Catrysse et al. (2015) examined the development of students' learning strategies during the transition from secondary to higher education. The results showed an increase not only in students' deep processing, analysing, and self-regulation but also in experienced lack of regulation for the whole group of students. These changes specifically occurred immediately after the transition from secondary to higher education. Before and after the transition, the use of these learning strategies was rather stable. Students who scored higher initially on a learning strategy showed less growth throughout these years than the students who initially scored lower on the strategy. The use of a memorizing strategy stayed rather constant throughout the research period, which may point to a survival strategy for learning when students make the transition from secondary to higher education.

The studies discussed in this section show that students can develop their learning patterns over time. These developments do not always follow a linear path, and developments are larger when the learning environment changes more. Stability in students' learning patterns may well be a consequence of a stable, non-changing learning environment.

\section{Methodological Advances in Learning Patterns Research}

This review focuses on the use of the ILS, as a whole or in parts (such as the ILS Short Version; Donche and Van Petegem 2008), for measuring (aspects of) learning patterns. Similar instruments are the MSLQ (Pintrich 2004), the SPQ (Biggs et al. 2001), the RASI (Entwistle and McCune 2004), and the Inventory Learning to Teach Process (ILTP; Endedijk et al. 2014a). The MSLQ and the ILS are both broad instruments that measure cognitive, motivational, and metacognitive aspects of student learning in higher education. The ILTP is also a broad instrument but focused on student teachers' learning. The (R)SPQ is focused on cognitive strategies and motivation only (see for a comparison Entwistle and McCune 2004; Vanthournout et al. 2009). All these instruments have in common that they are self-report instruments where students are asked to indicate on a Likert-scale the extent to which the activity, view, "- - or motive as described in the statement corresponds to their own way of learning, views or motives. Similarly, questionnaires have been used to study students' perceptions of their learning environment, for example the Course Experience Questionnaire 
(CEQ; Ramsden 1991; Law and Meyer 2011a), and the Inventory of Perceived Learning Environments Extended (IPSEE; Konings et al. 2012).

Recently, researchers have introduced other types of measurements to study students' learning patterns as well. For example, Endedijk et al. (2016) developed and used a structured digital log to measure multiple student teachers' learning activities in different learning circumstances. Their instrument is an example of multiple event measurement of students' regulation of learning, and their study demonstrates the added value of combining different types of instruments in research on student learning. Very recently, Catrysse et al. (2016) explored the use of a combination of eye-tracking and cued recall as more direct and online observation techniques to study students' deep and surface processing at a task specific level. Based on their findings, they suggest to combine eye tracking and cued recall as complementary research methodologies on student learning strategies.

During the last decade, researchers on student learning patterns have advanced their statistical methods to deal with more complex data in considerable ways. These developments are in line with advances in data analysis in other fields. For example, Ferla et al. (2008) used path analysis to study relationships between student cognitions and their effects on study strategies. Many studies reviewed in this paper have used Structural Equation Modelling (SEM) as an elegant way to deal with a large number of variables at the same time (e.g. De Clercq et al. 2013; Loyens et al. 2008; Martínez-Fernández and Vermunt 2015; Zhu et al. 2008). Fryer et al. (2016) used a longitudinal variant of SEM to analyse variables from two waves of data collection from the same students. In their large-scale study among students and their teachers, Donche et al. (2013) used multi-variate multi-level analysis to take account of the different levels the data represented (student, programme) when examining the relationship between learning strategies and teaching strategies.

From a longitudinal perspective, Coertjens et al. (2013b) compared three statistical techniques to analyse change in learning strategies over time: ANOVA, multi-level analysis, and multi-indicator latent growth (MILG) analysis. They concluded that the three techniques yield similar results concerning average trends but there are differences in the observed strength of the growth over time according to the different analysis techniques. Moreover, MILG seemed a more appropriate technique for detecting differential change over time. Therefore, in their own research on longitudinal change in students' use of learning strategies, they chose to use this multi-indicator latent growth analysis (Coertjens et al. 2013a).

Some researchers have used a person-oriented perspective to approach their data analysis. Rather than departing from a variable-oriented perspective, these researchers try to identify meaningful subgroups of students with similar scores on learning pattern variables. From this perspective, different variants of cluster analysis are often used to define groups of students. For example, Heikkilä et al. (2011) used latent class analysis for profiling students into homogeneous groups, while Vanthournout et al. (2013) used hierarchical cluster analysis for the same aim.

\section{Fostering the Quality of Students' Learning Patterns}

The espoused aims of higher education are quite universal around the globe and emphasize the importance of deep learning, critical thinking, independence, self-regulation, and using knowledge to benefit society, all elements of what is meant here with meaning-directed and application-directed learning and thinking. Therefore, it can be argued that meaning-directed and application-directed learning represent higher quality learning in higher education than 
reproduction-directed and undirected learning. Consequently, teaching in higher education should be aimed at fostering this high-quality student learning. A first, small-scale approach to improving student learning patterns from this perspective is through feedback, training, or support for specific groups of students. For example, Donche et al. (2012) found that some students preferred external sources for feedback information, such as the reliance on learner coaches, while other students preferred more internal sources and self-improvement. The authors conclude that a one-size-fits-all approach for learning pattern feedback is not a good option and might result in destructive friction for some learner groups. This study showed that particularly for students at risk, external and not internal sources for learning pattern feedback are preferable. Vermunt et al. (2014) argued for measures to support international students in their adaptation to foreign study environments. Students who have developed their learning pattern in their home country often need to adapt their way of studying and their study views to be successful in different educational cultures with different requirements abroad. In their view, a better understanding of how international students learn, think, and are motivated can help in developing better support for those students in adapting to a new study environment.

One of the implications of the differences between students in their learning patterns is that improving students' learning patterns may need a differentiated approach as well. A one-sizefits-all approach to support students in their learning pattern development may well represent a contradiction in terms. Endedijk et al. (2014a) presented a case for differential approaches to support student learning and provided us with many examples of how this can be achieved. Vanthournout et al. (2009) suggested that to develop more favourable learning patterns, adaptive instructional methods and remedial trajectories are needed. They argued for more differentiation in teaching methods to accommodate the different developmental needs of students with different learning patterns.

A second, more large-scale approach to fostering the quality of student learning patterns is through the use of innovative teaching-learning methods for all students. Many contemporary educational innovations are aimed at fostering students' meaning-directed and applicationdirected learning and discouraging reproduction-directed and undirected student learning patterns. Innovative pedagogies in higher education, such as not only problem-based learning and integrated contextual teaching but also pedagogies as project-based learning, case-based learning, and competency-based teaching, are aimed at improving the quality of student learning within regular disciplinary teaching, and not so much through extracurricular skills training, support or feedback (Bronkhorst et al. 2011; Ten Cate et al. 2004; Vermunt 2007). Recent research indeed showed evidence to support this claim. For example, Lycke et al. (2006) compared medical students in a problem-based learning (PBL) programme and in a traditional programme on their use of learning strategies, conceptions of learning, and academic outcomes at a Norwegian Medical school. The results showed that PBL-students made more use of self-regulated learning strategies and had more constructive conceptions of learning than students in the traditional medical programme. Van der Veken et al. (2008) compared third-year medical students in a conventional, an integrated contextual, and a problem-based curriculum in Belgium and The Netherlands in their scores on ILS-scales. Students in the problem-based curriculum showed less memorizing and rehearsing and more varied use of knowledge sources than students in the conventional curriculum. The students in the integrated contextual curriculum showed more structuring of subject matter by integrating different aspects into a whole. Concerning regulation strategies, students in the problem-based curriculum showed significantly not only more self-regulation in their choice of learning contents than the students in the other two curricula but also more lack of regulation than 
students in the integrated contextual curriculum. With regard to learning orientations, the students in the problem-based curriculum were least ambivalent compared to the other two curricula, and the students in the two innovative (PBL and integrated) curricula were most vocation-oriented in their learning motivation. A longitudinal follow-up study of the same research group (Van der Veken et al. 2009) revealed that the integrated curriculum resulted in lower lack of regulation when students progressed with their studies.

In a large-scale innovation study in Belgium, Baeten et al. (2014) showed that when students were gradually exposed to case-based learning after being used to a lecture-based teaching format, their reproduction-directed learning decreased and their autonomous motivation and assessment scores increased. These effects did not occur when the case-based innovation was introduced suddenly instead of gradually. The findings support the importance of a process-oriented approach to learning pattern development, in which there is a gradual transfer of control over students' learning from the educational environment to the students. A sudden introduction of case-based learning had an adverse effect, similar to what has been described as 'destructive friction' previously in the literature (Vermunt and Verloop 1999).

The studies discussed in this section point to the beneficial effect of certain pedagogies in higher education in terms of fostering the quality of student learning. The evidence presented here suggests that higher education pedagogies like problem-based learning, case-based learning, and integrated contextual teaching may foster meaning-directed and applicationdirected learning and discourage reproduction-directed and undirected learning.

\section{Discussion}

\section{Moving the Learning Patterns Perspective Forward}

In the following part, we aim to answer the question in which directions the present learning patterns perspective can be developed conceptually, theoretically, and empirically. Most of the discussed directions and perspectives below are based upon the reviewed studies but some directions are further away from the present knowledge base. These are further theoretical excursions, such as Fryer's contribution in this special issue, to identify possible bridges which can be built between often unconnected islands of investigation. In the first four sections, we critically discuss the basic four components of the model, and point to eight directions which might be fruitful to explore in order to broaden or deepen concepts within the present learning patterns model. In a fifth section, we present a range of research perspectives which can be valuable to further validate and develop the learning patterns model.

\section{Cognitive Strategies}

In contrast with a dichotomous view on processing strategies (deep versus surface) present in the SAL literature, the learning patterns model makes a more elaborate and further distinction of three main processing strategies, namely deep (relating/structuring and critical), stepwise (memorizing and analysing), and concrete processing strategies. Learning patterns research in the last decade has been mounting evidence about the presence of these dimensions, particularly in higher education contexts such as universities (Vermunt 2005) and university colleges (Donche and Van Petegem 2009) in and outside European contexts (Vermunt et al. 2014). In 
order to expand the present research on cognitive strategies in the learning patterns model, we emphasize two important directions.

A first conceptual direction is to further investigate the nature of cognitive strategies in specific contexts of learning and more specifically to clear out the variability of cognitive strategies on specific task level versus more domain and general level (see also Lonka et al. 2004). Although the past research has indicated both consistency and variability of processing strategies across different courses (Vermunt and Vermetten 2004) and time (Coertjens et al. 2013b), more in-depth studies are needed to examine the consistency and variability of processing strategies across tasks. Up till now, few studies have explored the possible flow of engaging in single or multiple cognitive strategies to perform learning tasks. It is especially on task level, which we expect that this configurational presence of cognitive activities which on a higher level can be understood as processing strategies might be present. The use of observation tools such as eye-tracking devices followed by cued recall might be particularly interesting in this regard, as they may point at the presence of different processing activities, sequence of activities, and strategies that can be task-specific (Catrysse et al. 2016).

A second direction, also situated on the task specific level is concerned with understanding and relating processing strategies in the learning patterns model to information processing (IP) strategies. Central in IP theories is how information is encoded and stored in memory (Craik and Lockhart 1972). Also in here, a distinction is made between surface processing and deep processing, albeit on a more specific level. Surface processing is related to how phonological representation of words is encoded when processing information, while deep processing is related to storing the semantic representation of words. Within this theory, it is assumed that deep processing as opposed to surface processing increases retention (Craik and Lockhart 1972; Richardson 2000). Connecting deep, stepwise, and concrete processing as conceptualized in the learning patterns model to depth and breadth of processing as known in IP theories may be a fruitful way forward to advance our understanding of student learning (see also Dinsmore et al. 2008; Lonka et al. 2004).

\section{Regulation Strategies}

Within the learning patterns model, a multiple perspective is present with regard to the metacognitive strategies students use to learn. In the existing framework of SAL research, the learning patterns model takes a distinct position, referring to the possible presence of internal and external sources of regulation when students learn and/or their absence in the case of lack of regulation. Although the learning patterns model offers a comprehensive insight in student regulation, the different dimensions can be further elaborated.

A third, conceptual direction is concerned with the concept of self-regulation which can be further deepened by making connection with current theoretical frameworks within SRL research (Winne and Hadwin 2008; Zimmerman and Schunk 2011). For a more detailed discussion on the dimensionality of SRL, we refer to the review studies of Zusho (2017) and Dinsmore (2017). In these models of self-regulation, a more phased view is understood of selfregulatory activities, making further distinction between self-regulatory activities in a forethought, performance, and evaluative phase. It seems particularly interesting to investigate to what extent the concept of self-regulation in the learning patterns model is related to other selfregulatory activities such as goal-setting, undertaking self-observations and making judgements with regard of goal attainment. It would allow more distinct views on how students exert metacognitive control when learning as well as enable to map in a more sequential phase, the nature and relationship between a more complex set of self-regulatory activities across time. 
A fourth direction is concerned with the concept of external regulation in the present learning patterns model. In the last two decades, collaboration between students and peer learning became more at the fore in socio-constructivist learning environments. This brings along that a lot of individual learning may also be influenced by interaction with significant others in the environment. Within SRL research, and more in particular from a socio-cognitive perspective, insights of the role of the social context, when individuals learn, have been growing (Järvelä et al. 2016). Different concepts such as co-regulation and socially shared regulation have been developed (Hadwin and Oshige 2011), and are important to interrelate with the present conceptualization of external regulation in learning patterns research. It could allow us to further deepen current understanding about the role of significant others when students learn such as peers, teachers, or parents (Räisänen et al. 2016).

\section{Motivation and Affect}

The learning patterns perspective emphasizes the role of study motives or learning orientations to regulate and process information. Based on phenomenographic analysis (Vermunt 1996), five distinct motives have been described which can be situated as more intrinsic (e.g. personal interest) or extrinsic (e.g. test oriented) in nature. Also, the absence of clear study motives (e.g. ambivalence) has been found to be a distinct feature when it comes to describe student motivation.

A fifth, conceptual direction is to further explore the framework of motivational in the learning patterns model, and investigate the value of further deepening and expanding the range of study motives that are now present in the model. The importance of motivational factors in current learning patterns research has been further explored in empirical studies, and sound interrelationships have been found between cognitive and regulation strategies and motivational factors based on models of Self-determination Theory (e.g. Donche et al. 2013; Liu et al. 2014) and Achievement Goal Theory (De Clercq et al. 2013); see also Fryer (2017).

A sixth direction is to deepen the affective component of student learning. Until now, this only has been marginally addressed, and deserves more attention. An interesting perspective is to look for possible connection or integration of the dimensionality of emotions within the control-value theory of achievement emotions of Pekrun (e.g. Goetz et al. 2016). Within this model, specific academic emotions such as anxiety, pride, joy, boredom, and anger are distinguished and interrelationships have been found with self-regulation (Pekrun 2006), learning strategies (Postareff et al. 2017), and approaches to learning (Trigwell et al. 2012).

\section{Learning Conceptions}

The learning patterns model is distinct in the SAL domain, as it focuses on conceptions about learning and relationship with learning strategies. Five different conceptions of learning are distinguished which have been widely investigated in past learning patterns research.

A seventh conceptual direction is to broaden the dimensionality of learning conceptions to encompass other closely related personal beliefs that are assumed to influence student learning. In particular, integration can be sought with the theoretical framework of epistemological beliefs (Pintrich 2004; Schommer 1990). Along this line of research, insights have been growing, about the development of beliefs about knowledge and knowing, basically starting from work of Perry (1970). Former research investigated the interrelationship between these beliefs and learning strategies, showing for instance that simple or naïve beliefs about knowledge are related to more use of rehearsal strategies and fewer use of organization 
strategies (selecting appropriate information to construct connections) when students learn (Dahl et al. 2005). Investigating the influence of these beliefs across time on student learning seems an interesting path for future research as well. It could enhance further understanding about the malleability of learning strategies over time.

An eighth direction is closely related to the theory on personal epistemology, and concerns competency beliefs. For instance, Dweck and Leggett's (1988) social cognitive model of motivation and integrating theories of motivation, personality, and development psychology could be useful to explore. Within this theory, a general distinction is made between incremental and entity beliefs. Students holding an incremental belief of intelligence regard it as a malleable factor which can be developed through learning, which is in contrast with student holding an entity belief, in which intelligence is regarded as a fixed trait. Previous research indicated important relationships between these contrasting type of beliefs and self-reported and behavioural measures of student learning and learning outcomes (Hofer 2001; Stump et al. 2014, Zhu et al. 2008).

\section{Directions for Future Learning Patterns Research}

As is evident from the discussed research themes found in the review sample, different conceptual and methodological developments in learning patterns research can be distinguished since 2004. This diversity has led to new questions both conceptually and methodologically. In what follows, we present five perspectives that are important to address in future learning patterns research to further validate and extend the theoretical base of learning patterns.

A first research perspective is the further exploration of the construct validity of the learning patterns model. Explicitly drawing relationships between neighbouring theoretical frameworks which have been put forward in the former section can be fruitful to further investigate the internal validity of the learning patterns model and interrelationships between adjacent concepts and theories. Explorations between one or more of the four situated components of the learning patterns model and other theoretical frameworks have been carried out in the last decade as present in the review set of 44 learning pattern related studies and other state-of-theart publications in the SAL domain (Gijbels et al. 2014). These insights offer various perspectives to further deepen our understanding of the components and interactions in the current learning patterns model. We also need to extend the current learning patterns model to incorporate affective, social-collaborative, domain-specific, and neurological features in the model and to study the interrelationships of the elements in this extended model.

A second perspective is related to exploration of the external validity of the learning patterns model. We need to continue studying learning patterns in more contexts and populations beyond the first years of higher education. In order to examine the cross-cultural nature of learning patterns, more research in international contexts is needed. It can enhance our current understanding about the consistency and variability of learning patterns across cultures (e.g. Vermunt et al. 2014). Besides the need for cross-cultural validation, also more in-depth research is needed to explore the validity of learning patterns in different educational contexts. Important explorations in this regard have been carried out in the context of teacher education, internships, and more informal learning contexts (e.g. Bakkenes et al. 2010; Endedijk et al. 2012; Vrikki et al. 2017). More research is needed studying learning patterns in a larger variety of contemporary learning environments, including social networks on the Internet, usage of mobile devices, massive online courses, tedtalks, etc. 
A third research perspective is further investigation of the criterion related validity of the learning patterns model by examining relationships with behavioural outcome variables. We need to increase our understanding of the predictive validity of learning patterns through broadening the conceptualisation and measurement of 'learning outcomes' beyond exam scores to include learning gains like enhanced motivation, critical engagement, self-efficacy, lifelong learning skills and attitudes, socio-communicative skills, and epistemological development. Moreover, it can be valuable to explore the relationship between learning patterns and more behavioural aspects, such as cognitive activities, study time, study pace, participation in activities, and interactions with staff and students in classrooms. An important connection can be made in here with the research literature and models of student engagement (e.g. Fredricks et al. 2004; Fredricks et al. 2016), in which behavioural measures of engagement are put central besides aspects of cognitive and emotional engagement (e.g. Krause and Coates 2008). Studies integrating these behavioural aspects are clearly lacking in the SAL field. With regard to the measurement of these behavioural activities in relationship with self-report measurement of student learning, it would be beneficial to use besides self-report measures also more direct or online measurement techniques such as observations (Endedijk et al. 2016). Intrapersonal research is interesting in this regard as well, in order to explore how self-reported measurements of student learning are related with for instance more behavioural measures of information processing, motivation, or affect as being observed by direct observation tools such as eye-tracking or brain scanning techniques (Catrysse et al. 2016; Trevors et al. 2016).

A fourth perspective to further examine is the role of interventions in the learning environment to understand stability, variability, and change of learning patterns. We need to develop and study the effects of powerful pedagogies and learning environments to foster active, self-regulated, meaning-directed, application-directed, collaborative, and high-quality student learning. Until now, an increasing set of learning pattern studies has pointed out that some components of learning patterns are more variable across time than others (Coertjens et al. 2012; Vermunt and Vermetten 2004). It would be particularly interesting to extend this research perspective, in order to understand how student learning can be influenced by educational innovations and interventions in longitudinal studies. An example is for instance the study of Lycke et al. (2006), in which changes in students' regulation strategies and conceptions of learning have been examined across different educational programmes (traditional versus problem based). Another example is the study of Van der Veken et al. (2009) in which changes in student learning were found between students endorsed in a conventional versus integrated contextual medical curriculum. Also, micro-level studies may be particularly interesting, examining the variability of learning patterns in specific task settings or domains of learning. For a substantial review of research in this area regarding strategic processing, we refer to the review of Dinsmore (2017).

A fifth and last research perspective is concerned with the integration of variable-oriented and person-oriented analyses in future ILS studies. In the last decade, person-oriented learning patterns studies and studies in the SAL domain (see also the review study of Asikainen and Gijbels 2017) have pointed at the intrapersonal level, how diverse and complex relationships of student learning variables can be (e.g. Heikkilä et al. 2011). It has widened the debate on the nature of learner profiles, taking into account for instance that learner groups can be typified as encompassing both meaning-directed and reproduction-directed learning or show the presence of more active or passive learner profiles (e.g. Donche and Van Petegem 2009). The methodological perspectives taken in these studies by using cluster analysis techniques or latent profile analysis are also important for theory development. It clearly shows a complementary 
picture when describing the quality and development of student learning patterns (Donche et al. 2010; Fryer et al. 2016; Postareff et al. 2017; Vanthournout et al. 2013).

\section{Concluding Remarks}

It is clear from this review that the research domain on learning patterns is lively and evolving in various directions. An important number of studies are further investigating the internal coherence of students' learning patterns and relationships with personal, contextual, and outcome variables, thereby adding further evidence to the components and interrelations of the learning patterns model. A growing number of studies are exploring new directions in learning patterns research, thereby advancing our knowledge about the cross-cultural validity of the model, the nature of and conditions for development over time, the impact of higher education pedagogies on the development of students' learning patterns, and the new research methodologies. Different perspectives for future research have been proposed to meet both conceptual and methodological challenges. Given the boundary crossing observed recently between different research traditions in the field of student learning in higher education (both conceptually and methodologically), a growing need for more collaboration and interdisciplinary research of learning patterns seems to be present. By discussing the state-of-the-art of current learning patterns research and the exciting pathways for further exploration and confirmation, we hope to have provided an inspiring roadmap for research collaboration for the next decade.

Open Access This article is distributed under the terms of the Creative Commons Attribution 4.0 International License (http://creativecommons.org/licenses/by/4.0/), which permits unrestricted use, distribution, and reproduction in any medium, provided you give appropriate credit to the original author(s) and the source, provide a link to the Creative Commons license, and indicate if changes were made.

\section{References}

*Studies are part of the review set

Ajisuksmo, C. R. P., \& Vermunt, J. D. (1999). Learning styles and self-regulation of learning at university: an Indonesian study. Asia Pacific Journal of Education, 19(2), 45-59.

*Al-Kadri, H. M. (2008). Improving inventory learning style. Neurosciences, 13(4), 426-429.

Asikainen, H., \& Gijbels, D. (2017). Do students develop towards more deep approaches to learning during studies? A systematic review on the development of students' deep and surface approaches to learning in higher education. Educational Psychology Review. doi:10.1007/s10648-017-9406-6.

Baeten, M., Struyven, K., \& Dochy, F. (2014). Do case-based learning environments matter? In D. Gijbels, V. Donche, J. T. E. Richardson, \& J. D. Vermunt (Eds.), Learning patterns in higher education: dimensions and research perspectives (pp. 273-294). New York: Routledge.

Bakkenes, I., Vermunt, J. D., \& Wubbels, T. (2010). Teacher learning in the context of educational innovation: learning activities and learning outcomes of experienced teachers. Learning and Instruction, 20, 533-548. doi:10.1016/j.learninstruc.2009.09.001.

*Biemans, H., \& Van Mil, M. (2008). Learning styles of Chinese and Dutch students compared within the context of Dutch higher education in life sciences. Journal of Agricultural Education and Extension, 14, 265-278. doi:10.1080/13892240802207700 .

Biggs, J. (1987). Student approaches to learning and studying. Melbourne: Australian Council for Educational Research.

Biggs, J., Kember, D., \& Leung, D. Y. P. (2001). The revised two-factor study process questionnaire: R-SPQ-2F. British Journal of Educational Psychology, 71, 133-149.

Bronkhorst, L., Meijer, P. C., Koster, B., \& Vermunt, J. D. (2011). Fostering meaning-oriented learning and deliberate practice in teacher education. Teaching and Teacher Education, 27, 1120-1130. doi:10.1016/j. tate.2011.05.008. 
Brown, A. L. (1987). Metacognition, executive control, self-regulation and other more mysterious mechanisms. In F. E. Weinert \& R. H. Kluwe (Eds.), Metacognition, motivation and understanding (pp. 65-116). Hillsdale: Erlbaum.

Cano, F., \& Garcia Berbén, A. B. (2014). University students' achievement goals and approaches to learning in mathematics: a re-analysis investigating learning patterns. In D. Gijbels, V. Donche, J. T. E. Richardson, \& J. D. Vermunt (Eds.), Learning patterns in higher education: dimensions and research perspectives (pp. 163186). New York: Routledge.

*Catrysse, L., Coertjens, L., Donche, V., Van Daal, T., \& Van Petegem, P. (2015). The impact of personality and motivation on the development of learning strategies. Pedagogische Studiën, 92, 308-323.

*Catrysse, L., Gijbels, D., Donche, V., De Maeyer, S., Van den Bossche, P., \& Gommers, L. (2016). Mapping processing strategies in learning from expository text: an exploratory eye tracking study followed by a cued recall. Frontline Learning Research, 4(1), 1-16. doi: 10.14786/flr.v4i1.192 .

*Coertjens, L., Donche, V., De Maeyer, S., Vanthournout, G., \& Van Petegem, P. (2012). Longitudinal measurement invariance of Likert-type learning strategy scales: are we using the same ruler at each wave? Journal of Psychoeducational Assessment, 30, 577-587. doi:10.1177/0734282912438844.

*Coertjens, L., Donche, V., De Maeyer, S., Vanthournout, G., \& Van Petegem, P. (2013a). Modeling change in learning strategies throughout higher education: a multi-indicator latent growth perspective. PloS One, 8(7), e67854. doi:10.1371/journal.pone.0067854.

*Coertjens, L., Van Daal, T., Donche, V., De Maeyer, S., Vanthournout, G., \& Van Petegem, P. (2013b). Analysing change in learning strategies over time: a comparison of three statistical techniques. Studies in Educational Evaluation, 39, 49-55. doi:10.1016/j.stueduc.2012.10.006.

Coffield, F., Moseley, D., Hall, E., \& Ecclestone, K. (2004). Learning styles and pedagogy in post-16 learning: a systematic and critical review. London: Learning and Skills Research Centre.

Craik, F. I., \& Lockhart, R. S. (1972). Levels of processing: a framework for memory research. Journal of Verbal Learning and Verbal Behavior, 11(6), 671-684.

Dahl, T. I., Bals, M., \& Turi, A. L. (2005). Are students' beliefs about knowledge and learning associated with their reported use of learning strategies? British Journal of Educational Psychology, 75, 257-273. doi: $10.1348 / 000709905 X 25049$.

De Clercq, M., Galand, B., \& Frenay, M. (2013). Chicken or the egg: longitudinal analysis of the causal dilemma between goal orientation, self-regulation and cognitive processing strategies in higher education. Studies in Educational Evaluation, 39, 4-13. doi:10.1016/j.stueduc.2012.10.003.

Dinsmore, D. (2017). Toward a dynamic, multidimensional research framework for strategic processing. Educational Psychology Review. doi:10.1007/s10648-017-9407-5.

Dinsmore, D. L., Alexander, P. A., \& Loughlin, S. M. (2008). Focusing the conceptual lens on metacognition, self-regulation, and self-regulated learning. Educational Psychology Review, 20, 391-409. doi:10.1007 /s10648-008-9083-6.

*Donche, V., \& Van Petegem, P. (2008). The validity and reliability of the short inventory of learning patterns. In E. Cools, H. van den Broeck, \& T. Redmond (Eds.), Style and cultural differences: how can organisations, regions and countries take advantage of style differences (pp. 49-59). Ghent: Vlerick Leuven Ghent Management School.

*Donche, V., \& Van Petegem, P. (2009). The development of learning patterns of student teachers: a crosssectional and longitudinal study. Higher Education, 57, 463-475. doi:10.1007/s10734-008-9156-y.

*Donche, V., Coertjens, L., \& Van Petegem, P. (2010). Learning pattern development throughout higher education: a longitudinal study. Learning and Individual Differences, 20, 256-259. doi:10.1016/j.lindif.2010.02.002.

*Donche, V., Coertjens, L., Vanthournout, G., \& Van Petegem, P. (2012). Providing constructive feedback on learning patterns: an individual learner's perspective. Reflecting Education, 8(1), 114-131.

*Donche, V., De Maeyer, S., Coertjens, L., Van Daal, T., \& Van Petegem, P. (2013). Differential use of learning strategies in first-year higher education: the impact of personality, academic motivation, and teaching strategies. British Journal of Educational Psychology, 83, 238-251. doi:10.1111/bjep.12016.

*Donche, V., Coertjens, L., Van Daal, T., De Maeyer, S., \& Van Petegem, P. (2014). Understanding differences in student learning and academic achievement in first year higher education: an integrative research perspective. In D. Gijbels, V. Donche, J. T. E. Richardson, \& J. D. Vermunt (Eds.), Learning patterns in higher education: dimensions and research perspectives (pp. 214-231). New York: Routledge.

Dweck, C. S., \& Leggett, E. L. (1988). A social-cognitive approach to motivation and personality. Psychological Review, 95, 256-273.

*Edelbring, S. (2012). Measuring strategies for learning regulation in medical education: scale reliability and dimensionality in a Swedish sample. BMC Medical Education, 12, 76. doi:10.1186/1472-6920-12-76.

*Edelbring, S., \& Wahlström, R. (2016). Dynamics of study strategies and teacher regulation in virtual patient learning activities: a cross sectional survey. BMC Medical Education, 16, 122. doi:10.1186/s12909-016-0644-y. 
Endedijk, M., Vermunt, J. D., Verloop, N., \& Brekelmans, M. (2012). The nature of student teachers' regulation of learning in teacher education. British Journal of Educational Psychology, 82, 469-491. doi:10.1111/j.20448279.2011.02040.x.

Endedijk, M. D., Donche, V., \& Oosterheert, I. (2014a). Student teachers' learning patterns in school-based teacher education programmes: the influence of person, context and time. In D. Gijbels, V. Donche, J. T. E. Richardson, \& J. D. Vermunt (Eds.), Learning patterns in higher education: dimensions and research perspectives (pp. 102-122). New York: Routledge.

Endedijk, M., Vermunt, J. D., Meijer, P., \& Brekelmans, M. (2014b). Students' development in self-regulated learning in postgraduate professional education: a longitudinal study. Studies in Higher Education, 39, 11161138. doi:10.1080/03075079.2013.777402.

Endedijk, M. D., Brekelmans, M., Sleegers, P., \& Vermunt, J. D. (2016). Measuring students' self-regulated learning in professional education: bridging the gap between event and aptitude measurements. Quality and Quantity, 50, 2141-2164. doi:10.1007/s11135-015-0255-4.

Entwistle, N., \& McCune, V. (2004). The conceptual bases of study strategy inventories. Educational Psychology Review, 16, 325-345. doi:10.1007/s1064800400030.

Entwistle, N. J., \& Ramsden, P. (1983). Understanding student learning. London: Croom Helm.

Evans, C., \& Vermunt, J. D. (2013). Editorial—styles, approaches and patterns in student learning. British Journal of Educational Psychology, 83, 185-195. doi:10.1111/bjep.12017.

*Ferla, J., Valcke, M., \& Schuyten, G. (2008). Relationships between student cognitions and their effects on study strategies. Learning and Individual Differences, 18, 271-278. doi:10.1016/j.lindif.2007.11.003.

Flavell, J. H. (1987). Speculations about the nature and development of metacognition. In F. E. Weinert \& R. H. Kluwe (Eds.), Metacognition, motivation and understanding (pp. 21-29). Hillsdale: Erlbaum.

Fredricks, J. A., Blumenfeld, P. C., \& Paris, A. H. (2004). School engagement: potential of the concept, state of the evidence. Review of Educational Research., 74, 59-109.

Fredricks, J. A., Filsecker, M., \& Lawson, M. A. (2016). Student engagement, context, and adjustment: addressing definitional, measurement, and methodological issues. Learning and Instruction, 43, 1-4. doi:10.1016/j.learninstruc.2016.02.002.

Friedrich, H. F., \& Mandl, H. (1986). Self-regulation in knowledge acquisition: a selection of German research. In G. Beukhof \& R. J. Simons (Eds.), German and Dutch research on learning and instruction: general topics and self-regulation in knowledge acquisition (pp. 43-99). The Hague: S.V.O.

Fryer, L. K. (2017). Building bridges: Seeking structure and direction for higher education motivated learning strategy models. Educational Psychology Review. doi:10.1007/s10648-017-9405-7.

*Fryer, L. K., Ginns, P., \& Walker, R. (2016). Reciprocal modelling of Japanese university students' regulation strategies and motivational deficits for studying. Learning and Individual Differences, 51, 220-228. doi:10.1016/j.lindif.2016.08.032.

Gijbels, D., Donche, V., Richardson, J. T. E., \& Vermunt, J. D. (Eds.). (2014). Learning patterns in higher education: dimensions and research perspectives. New York: Routledge.

Goetz, T., Sticca, F., Pekrun, R., Murayama, K., \& Elliot, A. J. (2016). Intraindividual relations between achievement goals and discrete achievement emotions: an experience sampling approach. Learning and Instruction, 41, 115-125. doi:10.1016/j.learninstruc.2015.10.007.

*Gulpinar, M. A. (2014). Learning styles of preclinical medical students. Hacettepe Universitesi Egitim Fakultesi Dergisi-Hacettepe University Journal of Education, 29(3), 68-80.

Hadwin, A. F., \& Oshige, M. (2011). Self-regulation, co-regulation, and socially shared regulation: exploring perspectives of social in self-regulated learning theory. Teachers College Record, 113(2), $240-264$.

*Heikkilä, A., Niemivirta, M., Nieminen, J., \& Lonka, K. (2011). Interrelations among university students' approaches to learning, regulation of learning, and cognitive and attributional strategies: a person oriented approach. Higher Education, 61, 513-529. doi:10.1007/s10734-010-9346-2.

*Helle, L., Laakkonen, E., Tuijula, T., \& Vermunt, J. D. (2013). The developmental trajectory of perceived selfregulation, personal interest, and general achievement throughout high school: a longitudinal study. British Journal of Educational Psychology, 83, 252-266. doi:10.1111/bjep.12014.

Hofer, B. K. (2001). Personal epistemology research: implications for learning and teaching. Educational Psychology Review, 13, 353-383.

Järvelä, S., Järvenoja, H., Malmberg, J., Isohätälä, J., \& Sobocinski, M. (2016). How do types of interaction and phases of self-regulated learning set a stage for collaborative engagement? Learning and Instruction, 43, 3951. doi:10.1016/j.learninstruc.2016.01.005.

*Konings, K. D., Brand-Gruwel, S., \& Van Merriënboer, J. J. G. (2011). The match between students' lesson perceptions and preferences: relations with student characteristics and the importance of motivation. Educational Research, 53, 439-457. doi:10.1080/00131881.2011.625155. 
*Konings, K. D., Brand-Gruwel, S., \& Elen, J. (2012). Effects of a school reform on longitudinal stability of students' preferences with regard to education. British Journal of Educational Psychology, 82, 512-532. doi:10.1111/j.2044-8279.2011.02044.x.

*Könings, K. D., Seidel, T., Brand-Gruwel, S., \& Van Merriënboer, J. J. G. (2014). Differences between students' and teachers' perceptions of education: profiles to describe congruence and friction. Instructional Science, 42, 11-30. doi:10.1007/s11251-013-9294-1.

Krause, K. L., \& Coates, H. (2008). Students' engagement in first-year university. Assessment and Evaluation in Higher Education, 33, 493-505. doi:10.1080/02602930701698892.

*Law, D. C. S., \& Meyer, J. H. F. (2010). Adaptation and validation of the Inventory of Learning Styles for quality assurance in a Hong Kong post-secondary education context. Quality in Higher Education, 16, 269283. doi:10.1080/13538322.2010.506717.

*Law, D. C. S., \& Meyer, J. H. F. (2011a). Relationships between Hong Kong students' perceptions of the learning environment and their learning patterns in post-secondary education. Higher Education, 62, $27-47$. doi:10.1007/s10734-010-9363-1.

*Law, D. C. S., \& Meyer, J. H. F. (2011b). Initial investigation of Hong Kong post-secondary students' learning patterns. Quality Assurance in Education: An International Perspective, 19, 335-356. doi:10.1108 /09684881111170069.

Lindblom-Ylänne, S., \& Lonka, K. (2000). Dissonant study orchestrations of high-achieving university students. European Journal of Psychology of Education, 15, 19-32.

Liu, W. C., Wang, C. K. J., Kee, Y. H., Koh, C., Lim, B. S. C., \& Chua, L. (2014). College students' motivation and learning strategies profiles and academic achievement: a self-determination theory approach. Educational Psychology, 34, 338-353.

Lonka, K., Olkinuora, E., \& Makinen, J. (2004). Aspects and prospects of measuring studying and learning in higher education. Educational Psychology Review, 16, 301-331.

*Loyens, S. M. M., Rikers, R. M. J. P., \& Schmidt, H. G. (2008). Relationships between students' conceptions of constructivist learning and their regulation and processing strategies. Instructional Science, 36, 445-462. doi:10.1007/s11251-008-9065-6.

*Lycke, K. H., Grøttum, P., \& Strømsø, H. I. (2006). Student learning strategies, mental models and learning outcomes in problem-based and traditional curricula in medicine. Medical Teacher, 28(8), 717-722. doi:10.1080/01421590601105645.

*Marambe, K. N., Vermunt, J. D., \& Boshuizen, H. P. A. (2012). A cross-cultural comparison of student learning patterns in higher education. Higher Education, 64, 299-316. doi:10.1007/s10734-011-9494-z.

*Martínez-Fernández, J. R., \& Vermunt, J. D. (2015). A cross-cultural analysis of the patterns of learning and academic performance of Spanish and Latin-American undergraduates. Studies in Higher Education, 40, 278-295. doi:10.1080/03075079.2013.823934.

Marton, F., \& Säljö, R. (1984). Approaches to learning. In F. Marton, D. Hounsell, \& N. Entwistle (Eds.), The experience of learning (pp. 36-55). Edinburgh: Scottish Academic Press.

Marton, F., Wen, Q., \& Wong, K. C. (2005). 'Read a hundred times and the meaning will appear...'. Changes in Chinese university students' views of the temporal structure of learning. Higher Education, 49, 291-318.

Meyer, J. H. F. (2000). The modeling of 'dissonant' study orchestration in higher education. European Journal of Psychology of Education, 15, 5-18.

Palinscar, A. S., \& Brown, A. L. (1984). Reciprocal teaching of comprehension-fostering and comprehensionmonitoring activities. Cognition and Instruction, 1(2), 117-175.

Pask, G. (1988). Learning strategies, teaching strategies, and conceptual or learning style. In R. R. Schmeck (Ed.), Learning strategies and learning styles (pp. 83-100). New York: Plenum Press.

Pekrun, R. (2006). The control-value theory of achievement emotions: assumptions, corollaries, and implications for educational research and practice. Educational Psychology Review, 18, 315-341. doi:10.1007/s10648-006-9029-9.

Perry, W. G. (1970). Forms of intellectual and ethical development in the college years: A scheme. San Francisco: Jossey-Bass.

Pintrich, P. R. (2004). A conceptual framework for assessing motivation and self-regulated learning in college students. Educational Psychology Review, 16, 385-407. doi:10.1007/s10648-004-0006-x.

Postareff, L., Mattson, M., Lindblom-Ylänne, \& Hailikari, T. (2017). The complex relationship between emotions, approaches to learning, study success and study progress during the transition to university. Higher Education, 73, 441-457. doi:10.1007/s10734-016-0096-7.

Räisänen, M., Postareff, L., \& Lindblom-Ylänne, S. (2016). University students' self-and co-regulation of learning and processes of understanding: a person-oriented approach. Learning and Individual Differences, 47, 281-288.

Ramsden, P. (1991). A performance indicator of teaching quality in higher education: the course experience questionnaire. Studies in Higher Education, 16, 129-150. 
Richardson, J. T. E. (1994). Cultural specificity of approaches to studying in higher education: a literature survey. Higher Education, 27, 449-468.

Richardson, J. T. E. (2000). Researching student learning: approaches to studying in campus-based and distance education. Buckingham: Open University Press and SRHE.

*Richardson, J. T. E. (2007). Mental models of learning in distance education. British Journal of Educational Psychology, 77, 253-270. doi:10.1348/000709906x110557.

*Richardson, J. T. E. (2010). Conceptions of learning and approaches to studying among white and ethnic minority students in distance education. British Journal of Educational Psychology, 80, 535-556. doi:10.1348/000709910x489283.

Schmeck, R. R. (Ed.). (1988). Learning strategies and learning styles. New York: Plenum Press.

Schommer, M. (1990). Effects of beliefs about the nature of knowledge on comprehension. Journal of Educational Psychology, 82, 498-504.

*Smith, L., Saini, B., Krass, I., Chen, T., Bosnic-Anticevich, S., \& Sainsbury, E. (2007). Pharmacy students' approaches to learning in an Australian University. American Journal of Pharmaceutical Education, 71(0), Article 120.

*Stump, G. S., Husman, J., \& Corby, M. (2014). Engineering students' intelligence beliefs and learning. Journal of Engineering Education, 103, 369-387. doi:10.1002/jee.20051.

Ten Cate, O., Snell, L., Mann, K., \& Vermunt, J. (2004). Orienting teaching towards the learning process. Academic Medicine, 79, 219-228.

*Timarova, S., \& Salaets, H. (2011). Learning styles, motivation and cognitive flexibility in interpreter training: self-selection and aptitude. Interpreting, 13(1), 31-52. doi:10.1075/intp.13.1.03tim.

Trevors, G., Feyzi-Behnagh, R., Azevedo, R., \& Bouchet, F. (2016). Self-regulated learning processes vary as a function of epistemic beliefs and contexts: mixed method evidence from eye tracking and concurrent and retrospective reports. Learning and Instruction, 42, 31-46. doi:10.1016/j.learninstruc.2015.11.003.

Trigwell, K., Ellis, R. A., \& Han, F. (2012). Relations between students' approaches to learning, experienced emotions and outcomes of learning. Studies in Higher Education, 37, 811-824. doi:10.1080 /03075079.2010.549220.

*Van der Veken, J., Valcke, M., Muijtjens, A., De Maeseneer, J., \& Derese, A. (2008). The potential of the inventory of learning styles to study students' learning patterns in three types of medical curricula. Medical Teacher, 30, 863-869. doi:10.1080/01421590802141167.

*Van der Veken, J., Valcke, M., De Maeseneer, J., \& Derese, A. (2009). Impact of the transition from a conventional to an integrated contextual medical curriculum on students' learning patterns: a longitudinal study. Medical Teacher, 31, 433-441. doi:10.1080/01421590802141159.

Van Rossum, E. J., \& Hamer, R. N. (2010). The meaning of learning and knowing. Rotterdam: Sense Publishers.

Vansteenkiste, M., Lens, W., \& Deci, E. L. (2006). Intrinsic versus extrinsic goal contents in self-determination theory: another look at the quality of academic motivation. Educational Psychologist, 41, 19-31.

*Vanthournout, G., Donche, V., Gijbels, D., \& Van Petegem, P. (2009). Alternative data-analysis techniques in research on student learning: illustrations of a person-oriented and developmental perspectives. Reflecting Education, 5(2), 35-51.

*Vanthournout, G., Gijbels, D., Coertjens, L., Donche, V., \& Van Petegem, P. (2012). Students' persistence and academic success in a first year professional bachelor program: the influence of students' learning strategies and academic motivation. Education Research International, Article ID 152747. doi: 10.1155/2012/152747.

*Vanthournout, G., Coertjens, L., Gijbels, D., Donche, V., \& Van Petegem, P. (2013). Assessing students' development in learning approaches according to initial learning profiles: a person-oriented perspective. Studies in Educational Evaluation, 39, 33-40. doi:10.1016/j.stueduc.2012.08.002.

Vanthournout, G., Donche, V., Gijbels, D., \& Van Petegem, P. (2014). (Dis)similarities in research on learning approaches and learning patterns. In I. D. Gijbels, V. Donche, J. T. E. Richardson, \& J. D. Vermunt (Eds.), Learning patterns in higher education: dimensions and research perspectives (pp. 11-32). New York: Routledge.

Vermunt, J. (1987). Learning styles and self-regulation. Paper presented at the annual Conference of the American Educational Research Association, Washington DC. ERIC Document ED 285900 TM 870481.

Vermunt, J. D. (1996). Metacognitive, cognitive and affective aspects of learning styles and strategies: a phenomenographic analysis. Higher Education, 31, 25-50.

Vermunt, J. D. (1998). The regulation of constructive learning processes. British Journal of Educational Psychology, 68, 149-171.

*Vermunt, J. D. (2005). Relations between student learning patterns and personal and contextual factors and academic performance. Higher Education, 49(3), 205-234. doi:10.1007/s10734-004-6664-2.

Vermunt, J. D. (2007). The power of teaching-learning environments to influence student learning. British Journal of Educational Psychology Monograph Series II, 4, 73-90. 
Vermunt, J. D., \& Endedijk, M. D. (2011). Patterns in teacher learning in different phases of the professional career. Learning and Individual Differences, 21(3), 294-302. doi:10.1016/j.lindif.2010.11.019.

Vermunt, J. D., \& Minnaert, A. (2003). Dissonance in student learning patterns: when to revise theory? Studies in Higher Education, 28, 49-61.

Vermunt, J. D. H. M., \& Van Rijswijk, F. A. W. M. (1988). Analysis and development of students' skill in selfregulated learning. Higher Education, 17, 647-682.

Vermunt, J. D., \& Verloop, N. (1999). Congruence and friction between learning and teaching. Learning and Instruction, 9, 257-280.

Vermunt, J. D., \& Vermetten, Y. J. (2004). Patterns in student learning: relationships between learning strategies, conceptions of learning, and learning orientations. Educational Psychology Review, 16, 359-384. doi:10.1007/s10648-004-0005-y.

*Vermunt, J. D., Bronkhorst, L. H., \& Martínez-Fernández, J. R. (2014). The dimensionality of student learning patterns in different cultures. In D. Gijbels, V. Donche, J. T. E. Richardson, \& J. D. Vermunt (Eds.), Learning patterns in higher education: dimensions and research perspectives (pp. 33-55). New York: Routledge.

*Vilppu, H., Mikkila-Erdmann, M., \& Ahopelto, I. (2013). The role of regulation and processing strategies in understanding science text among university students. Scandinavian Journal of Educational Research, 57, 246-262. doi:10.1080/00313831.2011.637229.

Vrikki, M., Warwick, P., Vermunt, J. D., Mercer, N., \& Van Halem, N. (2017). Teacher learning in the context of Lesson Study: a video-based analysis of teacher discussions. Teaching and Teacher Education, 61, 211-224. doi:10.1016/j.tate.2016.10.014.

Winne, P. H., \& Hadwin, A. F. (2008). The weave of motivation and self-regulated learning. In D. H. Schunk \& B. J. Zimmerman (Eds.), Motivation and self-regulated learning: theory, research, and applications (pp. 297-314). Mahwah: Erlbaum.

*Zhu, C., Valcke, M., \& Schellens, T. (2008). The relationship between epistemological beliefs, learning conceptions, and approaches to study: a cross-cultural structural model? Asia Pacific Journal of Education, 28, 411-423. doi:10.1080/02188790802468823.

Zimmerman, B. J., \& Schunk, D. H. (2011). Self-regulated learning and performance. An introduction and an overview. In B. J. Zimmerman \& D. H. Schunk (Eds.), Handbook of self-regulation of learning and performance (pp. 1-12). New York: Routledge.

Zusho, A. (2017). Toward an integrated model of student learning in the college classroom. Educational Psychology Review. doi:10.1007/s10648-017-9408-4. 